\title{
Microfoundations of a Dynamic Market Knowledge Capability, Empirical Explorations Under Conditions of Environmental Uncertainty: An Abstract
}

\author{
Rajiv Kashyap, Raza Mir, Shan Feng, and Mike Chen-Ho Chao
}

\begin{abstract}
Knowledge is a firm's most valuable and fundamental resource (Grant 1996; Wiklund and Shepherd 2003; Vargo and Lusch 2004). However, little attention has been given to its strategic antecedents. In the marketing domain, we are specifically concerned with the following: How do differences in strategy influence a firm's ability to develop market knowledge capabilities? How does environmental uncertainty interact with strategy to affect the development of market knowledge capabilities? The potential for market knowledge to confer competitive advantages is only realized when such knowledge is effectively applied to business processes such as new product development or technology deployment to generate cost and differentiation advantages. We conceive market knowledge as consisting of three interrelated dimensions: market knowledge routines, market knowledge culture, and market knowledge stores. In this study we develop the logic to tease apart the effects of various strategic firm orientations (customer, competitor, and technology) upon market knowledge under varying conditions of environmental uncertainty (customer, competitor, and technological). We conducted a key-informant cross-sectional survey of executives drawn from a variety of industries to test our hypotheses. Employing a hierarchical regression approach, we found support for many of our hypotheses, suggesting that strategic orientations provide a good starting point for the study of market knowledge capabilities. We also found that both customer and competitor orientations were positively associated with all dimensions of market knowledge capabilities but technology orientation was only associated with market knowledge culture. This study makes a unique contribution by elucidating the effects of various strategic orientations on the development of a market knowledge capability. Understanding how environmental factors shift managerial priorities for utilizing market knowledge capabilities is extremely insightful as we begin our quest for ways to effectively identify and appropriate value in constantly evolving markets.
\end{abstract}

References Available Upon Request

R. Kashyap $(\bowtie) \bullet$ R. Mir $\bullet$ S. Feng $\bullet$ M.C.-H. Chao

William Paterson University, Wayne, NJ, USA

e-mail: kashyapr@wpunj.edu; mirr@wpunj.edu; fengs@wpunj.edu; chaoc@wpunj.edu 